\title{
A Monistic Conclusion to Aristotle's Ergon Argument: the Human Good as the Best Achievement of a Human
}

\author{
(Penultimate Draft) \\ Please cite published version: \\ Archiv für Geschichte der Philosophie, vol. 103, no. 3, 2021, pp. 373-403. \\ https://doi.org/10.1515/agph-2018-0031
}

\author{
Samuel Baker \\ samuelbaker@southalabama.edu
}

\begin{abstract}
Scholars have often thought that a monistic reading of Aristotle's definition of the human good - in particular, one on which "best and most teleios virtue"

(Nicomachean Ethics I 7, 1098a17-18) refers to theoretical wisdom-cannot follow from the premises of the ergon argument. I explain how a monistic reading can follow from the premises, and I argue that this interpretation gives the correct rationale for Aristotle's definition. I then explain that even though the best and most teleios virtue must be a single virtue, that virtue could in principle be a whole virtue that arises from the combination of all the others (and this is what kalokagathia seems to be in the Eudemian Ethics). I also clarify that the definition of the human good aims at capturing the nature of human eudaimonia only in its primary case.
\end{abstract}

In the Olympics the prizes do not go to the finest and strongest men but to the competitors-for it is some of these who win - and so also in life, happiness is achieved only by those fine and good people who act rightly. (Nicomachean Ethics I 8, 1099a3-7) ${ }^{1}$

\section{Introduction}

Near the beginning of the Nicomachean Ethics Aristotle seems to lay the foundation for his practical philosophy with a stretch of reasoning known as the "ergon

\footnotetext{
${ }^{1}$ All translations are my own, though I have been influenced by published translations, especially Irwin 1999 and the translations found in Barnes 1995. I use the Oxford Classical Text edition of Aristotle's Greek, unless otherwise noted.
} 
argument." The conclusion of this argument is an account of the human good as an "activity of $<$ the rational part of $>$ the soul on the basis of virtue, and if there are more virtues than one, on the basis of the best and most teleios, and moreover in a teleios life" (I 7, 1098a16-18). The rest of the Nicomachean Ethics seems to build on this foundational definition in various ways (NE I 7, 1098a20-26).

One can distinguish, broadly speaking, two competing interpretations of the definition: either Aristotle is saying that the human good is activity of the soul on the basis of the single best virtue (to the exclusion of other virtues) or he is saying that the human good is activity of the soul on the basis of the complete set of virtues. These two interpretations of the definition generally correspond to two broad camps concerning Aristotle's theory of the human good in general: monists think that the human good is an activity on the basis of theoretical wisdom alone, while inclusivists think that the human good is an activity on the basis of many different virtues and perhaps even includes external goods such as honor, health or friends. ${ }^{2}$

In this paper, I present a novel interpretation of the ergon argument by way of responding to an often-repeated objection against a monistic interpretation of Aristotle's theory of the human good. The objection claims that the definition in Nicomachean Ethics I 7 cannot follow from the premises of the ergon argument when that definition is interpreted along monistic lines; this is considered a powerful objection because the ergon argument is supposed to contain Aristotle's own underlying rationale for defining the human good as he does. I begin by listing four assumptions that lead one to make this objection. After advancing an interpretation of the argument on which a monist reading of the definition can indeed follow from the premises, I explain how this interpretation offers reasonable alternatives to the four assumptions. I then make two important clarifications. First, though my interpretation of the argument does not strictly require a monistic reading of the definition of the human good, it does rule out the common inclusivist reading. And second, even if one does adopt a monistic interpretation of the

\footnotetext{
${ }^{2}$ What I have called "monism" is sometimes also called "exclusivism," "intellectualism," or "dominant end theory." What I have called "inclusivism" is sometimes also called "pluralism" or "comprehensivism." Inclusivism and monism do not exhaust the interpretive possibilities. There are also "gradationist" views, and I discuss them in section 8.2.
} 
definition, this need not commit one to monism about eudaimonia. This is because the definition aims at capturing the nature of human eudaimonia only in its primary case.

\section{Overview of the Ergon Argument}

At the beginning of Nicomachean Ethics I 7 Aristotle reminds his readers that he is seeking the end of things achievable in action (1097a22-23), which he earlier labeled "the human good" (NE I 1, 1094b7). He clarifies what he has in mind by saying that this best good is the most teleios end: something that is always such as to be rationally-chosen on account of itself and never on account of anything else (1097a33-34) while we desire everything else for its sake. Aristotle notes that eudaimonia "seems to be this most of all" (1097a34) and then explains that the best good, in virtue of being most of all an end, is also self-sufficient (1097b6-20). He then gives the ergon argument, which I divide into sections A through $\mathrm{F}$ along with a prefatory section.

In this paper I focus on sections $\mathrm{A}, \mathrm{C}$, and F, and so I include the text for these sections. In the prefatory section (1097b22-25), Aristotle reminds us that we still need to say more clearly what the best good is, and he suggests that we will do so if we grasp the ergon of a human.

[Section A] This is because in the case of a flautist, a sculptor, and every artisan, and generally, in the case of whatever has an ergon and an action, the good, that is,

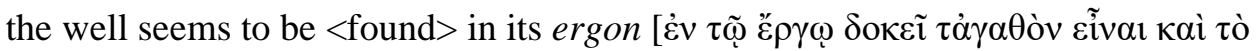
$\varepsilon \tilde{u}]$, and the same would seem to be true for a human, if he has an ergon. (1097b25-28)

In section B (1092b28-33), Aristotle gives two brief reasons to think that a human there is a human ergon, and then he asks:

[Section C] Whatever might this be? For living seems to be something that is common even to plants, but what we are seeking is that which is proper [ $\tau$ ò î́ıv] to a human. One must rule out, then, the life of nutrition and growth. What follows would be some sort of perceptive life, but this too would seem to be common to the horse 
and ox and every animal. What is left is some active life of that which has reason

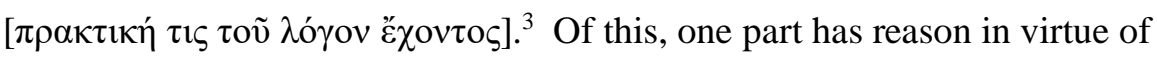
obeying reason, and another part actually has reason and thinks. And since this life is said in two ways ${ }^{4}$ we should be assuming life as activity since this seems to be called life in a primary way. (1097b33-1098a7)

In section D (1098a7-12), Aristotle says that an ergon accomplished well is an ergon accomplished on the basis of its proper virtue. In section E (1098a12-15) he repeats some important premises and then concludes:

[Section F] and if <all this> is so, then the human good turns out to be <an> activity of the <rational part of the human> soul on the basis of virtue, and if there are more

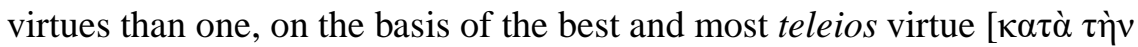

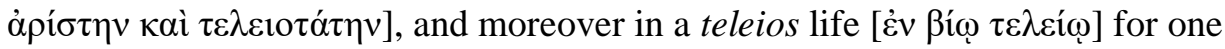
swallow does not make a summer, and in the same way neither does one day or a short time make one blessed and happy. (1098a16-20)

I have left two words untranslated: ergon and teleios. The word ergon ("work") I will discuss in section 4 , but here some remarks on the word teleios are in order.

Interpreters have clashed over the translation of teleios - those with monistic inclinations arguing it should be translated "final" or "end-like" while those with inclusivist inclinations often arguing it should be translated as "complete."5 The former largely draw on the teleological characterization of teleios in the immediate context of $N E$ I 7, where Aristotle seems to take for granted the etymological connection between the adjective teleios and the noun telos ("end"). He notes that "what is pursued for its own sake is more teleios that what is pursued for the sake of something else" and that "what is never chosen for the sake of something else is more teleios than those things that

\footnotetext{
${ }^{3}$ I translate "tou logon echontos"(1098a3-4) as "that which has reason" because this seems to me one way to capture the ambiguity of the Greek term logos, which often signifies a "rational account" but can also signify the faculty of reason (cf. Phys I 5, 189a7). For discussion of the term see Moss 2014 (with whose analysis I only partly agree).

${ }^{4}$ We can speak of "life" as a capacity for living or as the activity of living itself (cf. DA II 5).

${ }^{5}$ One may find an example of the former in Lear 2004, 8-46 and of the latter in Irwin 2012. I say that inclusivists "often" translate teleios as "complete," and that is because there are exceptions: Cooper 1999 and Walker 2011 both offer inclusivist interpretations of the definition, while conceding that "most teleios virtue" both refers to sophia and does not mean "most complete virtue."
} 
are chosen both for themselves and for the sake of it" (NE I 7, 1097a31-34). From this perspective, "the most teleios virtue" appears to be sophia, which Aristotle seems to identify as the single, teleologically highest virtue. On the other hand, inclusivist interpreters often note that since the phrase "in a teleios life" seems to mean "in a complete life" and since it occurs shortly after the phrase "most teleios virtue," it makes sense to interpret teleios in the same way both times. There are also others passages (such as $N E$ I 10, 1101a17-21 and VIII 4, 1156b7) where teleios seems to be naturally translated as "complete" and only with difficulty translated as "end-like." From this perspective, "most teleios virtue" seems to mean "most complete virtue."

I myself will continue to leave the word teleios untranslated, and I do so for three reasons. First, I believe that English is not particularly well equipped to convey the semantic range of teleios. ${ }^{6}$ Second, as I will argue below, Aristotle has good reason to think that being complete is one way of being end-like-yet this way of thinking about the question would seem to cut across the divisions of the traditional debate. Lastly and third, finding the best translation of teleios is not strictly necessary for determining whether a monistic reading of the definition of the human good can follow from the premises of the ergon argument - and it is this latter question that is the primary focus of this paper.

\section{The Objection and Its Background Assumptions}

In his article "Aristotle on Eudaimonia," J. L. Ackrill argues that since "the principle of the ergon argument is that one must ask what powers and activities are peculiar to and distinctive of man" and since man's ergon is identified as an activity of the rational part of the soul, where this includes activity of both reason itself and the nonrational part that partakes in reason (NE I 7, 1098a4-5 [section C]), it follows that "the only proper conclusion of the ergon argument" is one that identifies the human good with

\footnotetext{
${ }^{6}$ However, other languages are better equipped. For example, in Latin one might use the translation "perfectus," as we find in the translation of Grosseteste in Minio-Paluello 1974, and in French one might use the translation "achevé" — as we find in the translation of Gauthier and Jolif (1970) 2002.
} 
an activity of the soul on the basis of "all" its proper virtues. ${ }^{7}$ Many interpretersincluding Keyt, ${ }^{8}$ Cooper,,${ }^{9}$ Roche,${ }^{10}$ Curzer, ${ }^{11}$ Purinton,,${ }^{12}$ Müller, ${ }^{13}$ and Irwin ${ }^{14}$ — give, in some form or other, the same argument as Ackrill. ${ }^{15}$ They all argue against a monistic

\footnotetext{
${ }^{7}$ Ackrill (1974) 1980, 27. In the same passage, he states: “Aristotle's final conclusion adds what is usually taken to be a restriction to theoretical and contemplative thought, theoria, and to express therefore a narrow as opposed to an inclusive view of eudaimonia... However, there is absolutely nothing in what precedes that would justify such a restriction."

${ }^{8}$ Keyt 1983, 366 writes, "A second reason for favoring an inclusive rather than an exclusionary interpretation of the conclusion of the function argument is that the argument itself entails that the good for man is activity, not only in accordance with philosophical wisdom, but also in accordance with moral virtue and practical wisdom."

${ }^{9}$ Cooper (1987) 1999, 222, discussing the ergon argument, writes, "And since (see 1098a4-5) our rational power is a complex thing, having several aspects and functions, the perfected exercise of our specific nature will require several activities, the activities of the virtues that perfect the several aspects and functions of our rational power. Thus, Aristotle's own argument seems to require the conclusion that happiness is activity of complete virtue, i.e., activity of all the specifically human virtues, the ones belonging to our rational capacities." Later Cooper (2003) 2004 and 2012 denies the inclusivist position but
} does not respond to the objection here articulated.

${ }^{10}$ Roche 1988, 183 writes, "The ergon argument reveals that the peculiar function of man must be an activity in accordance with reason. It does not show that the function of man lies in the specialized activity of contemplative reason. So if D [the definition of the human good] is interpreted as D1 [i.e. along monistic lines], it is not supported by Aristotle's argument." Roche $(2014,238 n .71)$ makes more or less the same argument.

${ }^{11}$ Curzer 1990, 430 writes, "On the intellectualist interpretation, the 'best and most complete' criterion does not follow from the ergon argument but is just awkwardly tacked on to the ergon argument's conclusion."

${ }^{12}$ Purinton 1998, 261 writes, "[T]here has been widespread acknowledgment of the force of Ackrill's arguments against Hardie's 'intellectualist' view that Aristotle means to claim in $N E 1$ that happiness is nothing but activity in accordance with бopía: if one takes it that that is what Aristotle means to conclude from the function argument, one seems obliged to concede that this conclusion does not follow logically from the premises of the function argument."

${ }^{13}$ Müller 2003, 532-533 writes, "Versteht man (b) [viz. the addition "if there are more virtues than one, on the basis of the best and most teleios virtue"] jedoch in Bezug auf die verschiedenen ethischen und

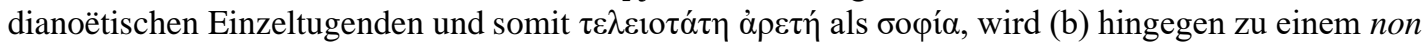
sequitur, das sich nicht aus den Prämissen des ě $p \gamma o v$-Arguments ableiten läßt.” Müller 2003, 533n.41 also suggests that this critique, in a way, goes back to Hardie 1965, 280.

${ }^{14}$ Irwin 2012, 516-518 writes, "The conclusions we draw from the function argument will partly depend on what we say about the claim that the distinctively human function is 'some sort of life of action of the having reason; of this one as obedient to reason, the other as having reason in thinking' (1098a3-5).[...] the function argument, therefore, includes the disputed clause [1098a3-5]. The human good cannot consist exclusively in the inherently rational activity either of theoretical study or of practical reason; it also consists in the virtuous activity that harmonizes the obedient part with practical reason. And so the function argument supports a pluralist conception of happiness."

${ }^{15}$ Even some scholars who think the definition ought to be interpreted monistically have conceded the force of this argument. For example, Kenny 1992, 29 writes, "Is the second half of the quoted sentence [i.e. "if there are more virtues than one, on the basis of the best and most teleios, and moreover in a teleios life," $N E$ I 7, 1098a17-19] a conclusion of the function argument, or something further added? It seems more natural to take it as part of the conclusion, and this is one of the strong points of the inclusive interpretation of book I... It must be agreed, I think, that the second half of the sentence, if interpreted in the dominant sense, is not a conclusion of the function argument, but a separate, self-standing development." See also Lawrence 2006, 59, discussed later in this section. Heinaman 1988, 36-37 concedes that a monistic reading cannot follow from the premises of the argument, but he considers this to be unproblematic because, on his 
reading of the definition of the human good because they believe it cannot follow from the premises of the ergon argument. They are lead to this view because they tend to make three to four inter-related assumptions about the argument.

First Assumption: the "good, that is, the well" of a human (1097b27) is the same thing as the human good (1098a16). Aristotle understands the "human good" (I 2, 1094b7) to be the best good achievable in action (I 2, 1094a18-22 and I 4, 1095a16-17), and he suggests that we will perhaps acquire this if we grasp the ergon of a human. In section A he explains that this is so because "the good, that is, the well [to eu]" of anything with an ergon and an action is found in the ergon (NE I 7, 1097b25-28). Ackrill and others assume that "the good, that is, the well" of a human (at 1097b27) is the same thing as "the human good" (NE I 2, 1094b7; I 7, 1098a16), and this is not a ridiculous assumption to make. If "the good, that is, the well" of a human is the same as the human good, that would naturally explain why Aristotle thinks section A would elucidate the concept of the human good.

Now when scholars criticize a monistic interpretation of the definition of the human good, they do not generally give interpretations of section A, but they often assume one not unlike that of Barney: "If an $x$ qua $x$ has as its function to $\Phi$, then the good of an $x$ qua $x$-its flourishing as an $x$-consists in $\Phi$-ing well." "The flourishing of an X, qua X" is her gloss on "the well" (to eu) in the phrase "the good, that is, the well" in section A, and she would seem to consider this to be the same as "the human good." Lawrence similarly equates "the good, that is, the well" with "the human good" in his interpretation of section $\mathrm{A}$ : "Where the $\mathrm{X}$ is something with a function, the $\mathrm{X}$-an good, i.e. the good of an $X$, consists in doing its function successfully or well." 17

interpretation, the ergon argument defines eudaimonia and not the best kind of eudaimonia. (See also Cleemput 2006, 153.) However, this interpretation seems to conflict with Aristotle's own characterization of the ergon argument as an attempt to define eudaimonia in the sense of the best good (NE I 7, 1097b2222).

${ }^{16}$ Barney 2008, 312. Roche 1988, 178 similarly gives an interpretation of section A on which "the good, that is, the well" of a human is equated with the human good: "[A]t NE 1097b25-28, Aristotle uses an inductive argument to show that 'for all things that have an ergon and an action (praxis) the good and the well (to eu) for that thing is believed to be in the ergon.' A flute-player, sculptor, or any artist, is said to realize his good (qua artist) in the performance of his work. And 'so it would seem to be for man, if indeed he has an ergon."'

${ }^{17}$ Lawrence 2009, 215. The emphasis is that of Lawrence. 
Second Assumption: The additions "on the basis of the best virtue" and "in a complete life" are mere optional elucidations of the proper conclusion of the ergon argument. Aristotle pretty clearly identifies "activity of the rational part of the soul on the basis of virtue" with "the well" of a human at $N E$ I 7, 1098a12 (in section D). If one notes this and also makes the first assumption, one would naturally suppose that the only proper conclusion of the ergon argument is that the human good is "activity of the soul on the basis of virtue" (1098a16-17). Indeed, scholars frequently express this thought by referring "activity of the soul on the basis of virtue" as the definition of the human good, ${ }^{18}$ and by reconstructing the ergon argument accordingly. ${ }^{19}$ They are then led to suppose that when Aristotle adds, "if there are more virtues than one, on the basis of the best and most end-like" (1098a17-18) and "in an end-like [i.e. complete] life" (1098a18), he is not listing further requirements that something must meet in order to be the human good, but rather giving optional clarifications of what has been already stated in the proper conclusion of the ergon argument. ${ }^{20}$

\footnotetext{
${ }^{18}$ I here list a few examples. McDowell 1980, 366 writes, “At 1.7.9-16. 1097b22-1098a20, Aristotle exploits the thesis that the ergon of man consists in rational activity, and the conceptual connections between the notions of ergon, excellence, and activity, in order to reach the conclusion that eudaimonia, the good for man, is rational activity in accordance with excellence." Cleemput 2006, 153 claims, "the ergon argument proper establishes that the human good consists in rational activity in accordance with excellence." He then says that the rest of the definition is added in a "rider to the ergon argument" (153). Bush 2008, 64 writes, "The human function determines the human good, and so we find, 'The human good turns out to be activity of the soul in accordance with virtue." Scott 2015, 132 (cf. 169) writes, "The second half [of $N E$ I 7] deploys the function argument, whose conclusion is that the human good consists in activity of the rational soul in accordance with virtue."

${ }^{19}$ Most reconstructions of the ergon argument explicitly present the proper conclusion of the ergon argument as "activity of the soul on the basis of virtue" (1098a16-17): see Glassen 1957, 320, Hutchinson 1986, 55, Achtenberg 1991, 62-63, and Natali 2010, 317. Exceptions include Gomez-Lobo, Pakaluk and Gottlieb. However, the conclusion according to Gomez-Lobo 1989, 182 ("A human being will be a good human being if and only if he produces good instances of activity with reason") or according to Pakaluk 2005,80 ("a good human being attains what is good for him") does not seem to correspond to what we find in the text. Gottlieb 2009, 66-67 does list the full definition as the conclusion of the argument, but her reconstruction suggests that the two further additions are just optional clarifications.

${ }^{20}$ For example, Irwin 2012, 503 writes, "He [Aristotle] explains 'in accord with virtue' by adding that the relevant activity must be in accord with final virtue..." and later at 518 says, "In speaking of complete virtue Aristotle emphasizes the organic character of happiness and of the virtuous activity that achieves it" (emphasis added both times). In the first quotation Irwin presents what he takes to be the monist interpretation and in the second his own inclusivist interpretation. In both cases, he seems to think that one must understand "if there are more virtues than one, on the basis of the best and most teleios virtue" to be a kind of elucidation of "on the basis of virtue." Similarly, Purinton $(1998,271)$ considers it "quite clear" that "the claim that happiness is activity in accordance with 'the best and most perfect virtue' [is] a mere reformulation of $[\ldots]$ the claim that it is activity in accordance with virtue" (emphasis added).
} 


\section{Third assumption: For an activity to count as the ergon of a human it must} involve the activity of both parts of the soul that "have reason" (1098a3-4). ${ }^{21}$ In section C, Aristotle says that the human ergon is activity "of the part [of the soul] having reason" (1098a3-4), and he then clarifies that by "part having reason" he had in mind two parts: "one having reason in virtue of obeying reason, and another actually having reason and thinking" (1098a4-5). ${ }^{22}$ In NE I 13 he explains that the virtues of character are proper to the part that obeys reason, and the virtues of thought are proper to the part that has reason strictly speaking (1103a1-5). Ackrill and others have argued that since the human good is identified as an instance of the human ergon, and the human ergon is identified as activity of the part of the soul having reason, where this includes both parts that have reason, the human good must consequently include the activity of all the virtues - those of character as well as those of thought. Thus, either implicitly or explicitly Ackrill and others understand Aristotle's characterization of the human ergon in section $\mathrm{C}$ to mean that an activity cannot count as an instance of the human ergon unless it involves activity of both parts of the soul that can be said to have reason. ${ }^{23}$

Here we should also note that any inclusivist who made the second assumption but not the third would find themselves with an awkward result. For it would then be possible to interpret "activity of the soul on the basis of virtue" in a way that could be satisfied by two different types of activity: either virtuous activity of the part that has reason in itself, or virtuous activity that involves the part that obeys reason. Yet such a

\footnotetext{
${ }^{21}$ By using the language of "part" to describe Aristotle's position, I of course do not mean to commit Aristotle to a Platonic notion of parts of the soul. Aristotle does not seem to think it is necessary for the practical philosopher to have a position on this issue (cf. NE I 13, 1102a28-32).

${ }^{22}$ Like most commentators, I take it that "the part that actually has reason and thinks" (NE I 7, 1098a4-5) includes both theoretical and practical reason. However, Joachim (1951) 1962, 50, and Bush 2008, 63 propose that this part be identified exclusively with practical reason. I will not discuss their suggestion in depth, but see Auferheide 2015, 54 for a response to Bush, and see Kraut 1979, 469n.6 for a response to the suggestion of Joachim (1951) 1962, 50, apparently followed by Bush 2008, 63, that prakitkē [zoē] tis at $1098 \mathrm{a} 3$ should be understood as "a certain practical life" (which involves exclusively practical activity) and not as "a certain active life" (which would include practical and/or theoretical activity).

${ }^{23}$ For Ackrill, Cooper and Irwin, see the quotations in the footnotes at the beginning of this section. Roche 1988, 182-183 arguing similarly, writes, "Does the internal evidence suggest that D [the definition of the human good] should be interpreted along the lines of the intellectualist interpretation [...]? The answer is clearly "No." For there is nothing in the ergon argument which suggest that the human good should be confined to activities in accordance with contemplative virtue. On the contrary, the distinction made in A2 [NE I 7, 1098a3-5] and B [NE I 7, 1098a12-14], suggests that the exercise of moral virtue is included in the ergon of man, hence, the human good."
} 
disjunctive interpretation would seem to be unacceptable since we are looking for the best - that is, teleologically highest-good.

Fourth Assumption: the key explanatory middle term of the argument inclines one to think that the human good would involve both practical and theoretical activity.

In Posterior Analytics II 11, Aristotle gives examples of syllogisms with explanatory middle terms, one of which answers the question: "Why did the Athenians become involved in the Persian War?" The intended syllogism seems to run as follows:

Athenians were the initial aggressors.

Initial aggressors are warred upon.

Therefore, the Athenians were warred upon. ${ }^{24}$

"Initial aggressors" is here the explanatory middle term because it provides the reason for the conclusion. The Athenians became involved in the Persian War because they first invaded the Persian regional capital of Sardis (Post II 11, 94a37-b2). Now unlike this example, the ergon argument is composed of many premises and has more than one explanatory middle term. However, there is one key explanatory middle term, and this is the middle term that provides the direct link to the term "the human good" (

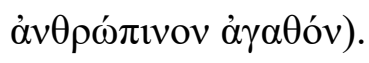

Interpreters have not generally articulated what exactly they take the key explanatory middle term of the ergon argument to be, but they implicitly assume one that would make it unlikely for the human good to consist exclusively in theoretically wise activity. Many assume that the key explanatory middle term is (roughly) the "flourishing" of a human. ${ }^{25}$ On such an interpretation, an abbreviated form of Aristotle's reasoning in the ergon argument would be as follows:

The human good is the flourishing of a human.

The flourishing of a human is the activity of the human soul on the basis of virtue.

\footnotetext{
${ }^{24}$ This is a slightly modified version of the syllogism found in Johansen 2012, 41.

${ }^{25}$ Barney 2008, in her interpretation of section A, effectively makes "the flourishing of a human" the key explanatory middle term of the ergon argument. The idea that the human good is the flourishing of a human also plays a central role in the neo-Aristotelian ethical theories of Foot 2001 and Kraut 2009.
} 
Therefore, the human good is the activity of the human soul on the basis of virtue.

Here "flourishing of a human" serves as an explanatory middle term, and since the term suggests the exercise of all distinctively human powers, it leads one to interpret "on the basis of virtue" as "on the basis of all the virtues." 26

Gavin Lawrence takes a different key explanatory middle term to be a work in the ergon argument - the "success of a human"- - but this also leads him to think that an inclusivist interpretation of the definition of the human good follows most naturally from the premises. Consider the following passage:

[I]n favor of the comprehensive <reading of "best and most teleios virtue">, one might compare eyesight: the good of the eye, or success in the eye, consists in performing its function, seeing, well, i.e. in accord with the excellence proper to seeing; and if there are several, then surely in accord with the best, i.e. most complete, set. There are various defects of sight, and various aspects to its correctness - and one needs them all to enjoy perfect seeing. ${ }^{27}$

Since the human good is the "success" of a human, it should likewise be an activity on the basis of "best, i.e. most complete, set" of virtues. Thus, Lawrence concedes that on his interpretation of the ergon argument, a monistic interpretation does not seem to follow from the premises. This is a surprising judgment on his part because he explicitly favors a selective reading of the phrase "the best and most teleios virtue," mostly on the basis of evidence for monism elsewhere in the $N E .^{28}$

But how do these four assumptions relate to one another? As we just noted, the fourth assumption takes something like "the flourishing of a human" or "the success of a human" to be the same as the human good, and in order to find these terms in the text,

\footnotetext{
${ }^{26}$ Irwin 2012, 495 seems to think that "the realization of human nature and the human soul" is the explanatory middle term of the argument, and this of course leads him to think that the human good should be the actualization of all our distinctively human faculties. Scott 1999, 231 similarly claims, "the underlying premise of [the ergon argument] is that eudaimonia "must consist in some activity that expresses what we are." However, unlike Irwin, Scott thinks that eudaimonia can consist in contemplation alone, and so is led to argue that there must two different human natures: nous and the composite. He does not attempt to explain how these two human natures interact.

${ }^{27}$ Lawrence 2006, 59.

${ }^{28}$ Lawrence 2006, 59. He thinks that one could understand only retrospectively that the relevant phrase should be read "selectively". Yet if this is the correct interpretation of the definition, it should of course be able to follow from the premises of the ergon argument, but Lawrence nowhere says how it could.
} 
one would naturally understand them as glosses on "the well" in the phrase "the good,

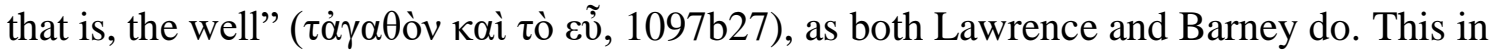
turn leads one to identify the human good with "the good, that is, the well" of a human"-which is the first assumption. The first assumption then leads one to think that the proper conclusion of the ergon argument is that the human good is "activity of the soul on the basis of virtue," and this in turn pushes one to understand the two additions ("on the basis of the best and most teleios virtue" and "in a teleios life") as optional elucidations - which is the second assumption. Finally, the third assumption would also seem to be required by inclusivist reading of the definition, insofar as inclusivists reject the idea that the definition of the human good could be satisfied by two quite different goods: virtuous theoretical activity or virtuous practical activity.

\section{The Alternative Concept of Ergon}

If one wishes to argue that a monistic interpretation of the definition of the human good can indeed follow from the premises of the ergon argument, one must try to find a plausible interpretation of the argument that nevertheless allows one to reject the four assumptions (or at least a sufficient number of them). I believe that one can do this but it requires rejecting the widespread assumption that in the ergon argument Aristotle understands the ergon of an $\mathrm{X}$ to always be the proper activity of an $\mathrm{X}$. Instead, we should maintain that in NE I 7 the ergon of an $\mathrm{X}$ is taken to be an activity in some cases but a product (beyond the activity) in others, in accordance with the sort of the thing that the $\mathrm{X}$ is. Thus, while the ergon of the flautist is a performance, the ergon of a sculptor is not sculpting, but a sculpture. And while the ergon of a human is an activity of living, the ergon of a housebuilder is not housebuilding, but a house. Elsewhere I have argued at length that Aristotle employs this concept of an ergon in Nicomachean Ethics I 7. ${ }^{29}$

However, I will here just give two brief reasons to think the interpretation is correct. First, this alternative concept is required if one thinks, as many do and as

\footnotetext{
${ }^{29}$ See Baker 2015. I should also perhaps note that the language of "product" is not perfect since in English it does not seem inappropriate to speak of some proper activities (like singing or dancing) as products. However, the key thought is just that for some things the ergon is a proper activity while for others it is something external beyond the proper activity.
} 
Eudemian Ethics II 1 explicitly states, that the ergon of an $\mathrm{X}$ is the end for the sake of which an $\mathrm{X}$, as an X, exists (1219a8). This is because there is overwhelming evidence that while Aristotle considers some proper activities to be ends, he considers others not to be ends, but essentially means-to-ends (cf. Meta $\Theta$ 6, 1048b18-35). These latter activities have an internal reason to stop and this is the essential ordering to their end. Thus, sculpting is a means-to-an-end and an individual instance of sculpting naturally comes to a stop when its end - the sculpture - is produced. Similarly, housebuilding is a means-toan-end and an individual instance of housebuilding naturally comes to a stop when its end - the house - is produced. Aristotle would also seem to subscribe to this distinction in the $N E$ (cf. I 1, 1094a1-6 and X 4, 1174a19-23). ${ }^{30}$ Thus, if he thinks that the ergon of an $\mathrm{X}$ is the end of an $\mathrm{X}$, as an $\mathrm{X}$, he should also subscribe to the alternative concept of an ergon. $^{31}$

Second, only if one assumes that Aristotle is using this alternative concept in $N E$ I 7 can Aristotle's reasoning in the passage be what it ought to be. The conclusion of the ergon argument is a definition of the "human good" (1098a16), and this quasi-technical term was introduced at $N E$ I 2, $1094 \mathrm{~b} 7$ as a label for the best good achievable in action by humans. There Aristotle explained that the best achievable good is something that we rationally-desire $(\beta o v \lambda o ́ \mu \varepsilon \theta \alpha)$ for its own sake and not for the sake of something else, and it is something for whose sake we choose all other things (I 2, 1094a18-22). ${ }^{32}$ Thus, if we are to remain faithful to Aristotle's own way of thinking about the human good, we must understand him to be arriving at his definition of the human good precisely because this is the best achievement of a human. Thus, the key explanatory middle term of the ergon argument should be "best achievement of a human."

Only the alternative concept of an ergon allows this to be so, and this is because it allows the claim of section A to be this:

\footnotetext{
${ }^{30}$ Anagnostopoulos 2017 also argues that even though the distinction in Physics III 1 (between the activity of something complete and the activity of something incomplete) is more fundamental than the distinction in Metaphysics $\Theta 6$ (between complete and incomplete activities), this does not undermine the latter distinction's "applicability in certain contexts, especially ethical contexts" (208).

${ }^{31}$ See Baker 2015, 246-247.

${ }^{32}$ It is also worth noting that Aristotle understands this teleological ordering to be independent of any individual human psychology. On this point, note that at the very beginning of the ethics, Aristotle says that when an activity issues in a work beyond that activity, as sculpting issues in a sculpture beyond the activity of sculpting, the work in this case is "better by nature" than the activity (NE I 1, 1094a5-6; my emphasis).
} 
For anything with an ergon and an action, the good in the sense of the excellent achievement

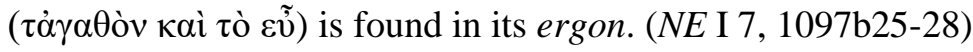

The basic thought here is: For anything that has an ergon and an action, the good in the sense of the excellent achievement is its ergon achieved well. Thus, for a sculptor, the good in the sense of the excellent achievement is the sculpture achieved well (i.e. an excellent sculpture). Such a claim is obviously relevant to determining the best achievement of a sculptor since the best achievement of a sculptor will be the superlatively excellent achievement of a sculptor. Similarly, the best achievement of a human will be a superlatively excellent achievement of a human - that is, the excellent achievement of a human with any better-making features that there may be.

Here it is worth appreciating this point by way of contrast. For if we assume that the ergon of an $\mathrm{X}$ is always the proper activity of an $\mathrm{X}$, then the reasoning of section $\mathrm{A}$ (as interpreted above) would not be relevant for determining the best achievement of an $\mathrm{X}$. This is because Aristotle makes the claim of section A with respect to "a flautist, a sculptor, every craftsman and generally anything with an ergon and an action" (NE I 7, 1097b26); yet the best achievement of a sculptor is clearly not a certain instance of sculpting well but rather a certain excellent sculpture (cf. NE I 1, 1094a5-6). Thus, in order for section A to contain the rationale that it ought to contain, Aristotle needs to be employing the alternative concept of an ergon. ${ }^{33}$

\section{Two Ways of Reading the Full Definition of the Human Good in Relation to the Premises of the Ergon Argument}

To help us appreciate the interpretation of the ergon argument that I offer in the next section, I here draw a distinction between two different ways of thinking about the full definition of the human good in section F. I divide this last section of the ergon argument into three parts — a preliminary definition and two additions:

\footnotetext{
${ }^{33}$ See Baker 2015, 261-263.
} 
[Prelim. Def.] The human good turns out to be activity of the < rational part of the human> soul on the basis of virtue (1098a16-17).

[Addition 1] ...if there is more than one virtue, on the basis of the best and most teleios virtue (1098a17-18)

and

[Addition 2] ...moreover, in a teleios life. (1098a18)

Now in giving the two additions to his preliminary definition of the human good is Aristotle (1) listing additional criteria that something must meet if it is to be the human good or is he (2) merely clarifying what criteria are already implicit in his preliminary definition? I call option (1) the additional criteria view, and I call option (2) the implicit criteria view. Those who argue that a monistic reading of the definition of the human good cannot follow from the premises of the argument almost inevitably subscribe to the implicit criteria view (as I mentioned above). Those who think that a monistic reading can indeed follow from the premises can most straightforwardly make their case by subscribing to the additional criteria view. ${ }^{34}$ In what follows I shall offer an interpretation of section A that allows one to reconstruct the ergon argument in a way that is compatible with the additional criteria view. ${ }^{35}$

\section{The Ergon Argument and the Additional Criteria View}

My proposed interpretation of section A is compatible with both the implicit criteria view and the additional criteria view: "If anything has an ergon and an action, the excellent achievement of that thing (as such) is its ergon achieved excellently/well." To make it consistent with the implicit criteria view, one should equate "the excellent achievement" of a human with the best achievement of a human (that is, the human

\footnotetext{
${ }^{34}$ See Baker 2015, 259-260 for a reconstruction of the ergon argument in premise-conclusion format that is compatible with the additional criteria view.

${ }^{35}$ Two clarifications are perhaps in order. First, I am not claiming that every interpretation of the ergon argument must neatly fall into one of these two views. And second, I am not making any claims about which view must be adopted by monists or inclusivists.
} 
good). To make it consistent with the additional criteria view, one should not equate the two. On this latter reading, we can understand Aristotle to be arriving at his full definition of the human good, by first identifying the class of thing that the human good falls under, and then by systematically listing various features that the human good would need to possess in order to be the best achievement of a human.

The method seems reasonable. If we want to determine the best achievement of any given thing, it makes sense to determine what the proper achievement (or proper work) of that thing is, and this is the ergon of that thing. One should then list whatever features are necessary for that proper achievement to be as good as possible. Since the human good is the best achievement of a human, Aristotle first determines the proper achievement (or proper work) of a human as "active life" of the part of the human soul having reason (1098a3-4) by which he means "an activity of the $<$ human $>$ soul on the basis of reason or not without reason" (1098a7-8; cf. 13-14). He then lists relevant features that serve to narrow in on what the best achievement of a human is: first, "on the basis of virtue" (1098a17) but then, "if there are more virtues than one, on the basis of the best and most teleios virtue" (1098a17-18) and finally, "in a teleios life" (1098a18). Here the last two additions are not optional (even if valuable) elucidations of the preliminary definition, as they are on the implicit criteria view, but additional criteria that Aristotle must add if he is to properly define the human good as the best achievement of a human being.

One could employ the same method in order to determine what, for Aristotle, is the best achievement of a poet. A poet's proper achievement will be a poem (cf. NE IX 9, 1167b33-1168a2). Yet in order for a poem to be the best achievement of a poet, further features will need to be added: it will need to be achieved well, that is, on the basis of the virtue proper to a poet, and also, if there are more genres of poetry than one-which there are since there is epic, tragedy, comedy, lyric, etc.-it will need to be an excellent poem of the best genre. Indeed Aristotle appears to identify the best poetic genre as tragedy when he argues in Poetics 26 that tragedy is a better genre than epic. Thus, the best achievement of a poet will be: "a poem achieved on the basis of poetic virtue, and if there are more genres than one, such a poem of the best genre." And so while an excellent 
poem in any genre counts as an excellent achievement of a poet, only an excellent tragedy could count as the best achievement of a poet.

One could likewise use this method to determine what, for Aristotle, would be the best achievement of a sculptor, to use an example from the ergon argument ( $N E$ I 7, 1097b25). The proper achievement of a sculptor will be a sculpture, but in order for it to be the best achievement of a sculptor, further features must be added: it will need to be achieved well, that is, on the basis of the virtue proper to a sculptor (cf. NE VI 7, 1141a912), but it also will need to have any possible "better-making" features. For example, in order to be the best achievement of a sculptor, an excellent sculpture would need to be of the most excellent subject matter: "equally in the case of painting, one might be a good imitator [mimētēs] but would nevertheless not be praised if one should not set as one's aim to imitate [mimeisthai] the noblest things [to kallista]" (MM I 19, 1190a30-32).

Because painting and sculpture are imitative arts their value will largely derive from what they imitate; thus, while there can be an excellent sculpture of a mouse, it will not be as good as an excellent sculpture of a human. ${ }^{36}$ Moreover, the best sculpture will need to be constructed out of optimal material because "to the extent that the material is prepared prepared, the finer the work of the art necessarily is" (Pol VII 4, 1326a1-3; cf. NE I 10, 1101a3-6). An excellent sculpture made out of mud or clay is just not as good as an excellent sculpture made out of marble or bronze. ${ }^{37}$ The best achievement of a sculptor, then, will be a sculpture achieved on the basis of virtue, and if there is more than one

\footnotetext{
${ }^{36}$ On this point, see Parts of Animals I 5, where in the course of arguing that one should study not only the celestial bodies but also the less noble terrestrial animals, Aristotle writes, "For even among the animals

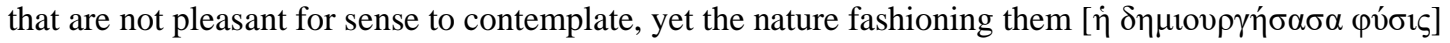
gives extraordinary pleasures to those who are capable of discovering their causes and are naturally

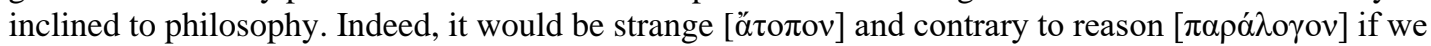
enjoy contemplating images of them, because we simultaneously contemplate the fashioning art [ $\tau \grave{v} v$

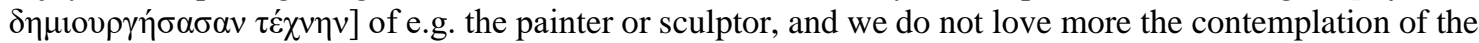
things themselves framed by nature, at least insofar as we are able to discern the causes" (645a7-15). (I translate the Greek in Louis 1956.) In this passage Aristotle not only takes it for granted that sculpture is a mimetic art (PA I 5, 645a13), but also assumes that one would naturally love and enjoy contemplating the thing imitated, which is fashioned by nature, more than its imitation, which is fashioned by art (PA I 5 , 645a10-15). A reasonable explanation for this latter claim is that Aristotle understands the value of a mimetic artwork to derive largely from the value of its subject matter. Similarly, one should note, Aristotle takes the value of a science to derive primarily from the value of its subject matter (cf. NE VI 7 and $D A$ I 1).

${ }^{37}$ Yet it is worth clarifying that Aristotle would also presumably think that the material of a sculpture must suit the artistic goal of that sculpture (cf. Phys II 9, 200a30-b8).
} 
subject matter, concerning the noblest subject matter, and moreover, constructed out of the best material.

I give these examples in order to help us appreciate how Aristotle's reasoning in the ergon argument could very well terminate in a definition that picks out a single type of virtuous activity - namely, activity on the basis of sophia - as the human good. The idea is that the addition "if there is more than one virtue, on the basis of the best and most teleios virtue" serves as a further condition that a virtuous activity would need meet in order to qualify as the best achievement of a human. Similarly, the addition "if there is more than one genre, of the best genre" serves as a further condition that an excellent poem would need to meet in order to qualify as the best achievement of a poet, and the addition "if there is more than one subject matter, concerning the noblest subject matter" serves as a further condition that an excellent sculpture would need to meet in order to qualify as the best achievement of a sculptor.

\section{Alternatives to the Assumptions Behind the Objection}

I now show why the interpretation of the argument here proposed can reject each assumption earlier listed in section 3.

Alternative to the First Assumption: "the good, that is, the well" of a human (1097b27) is not the same as the human good. The former is roughly related to the latter as genus to species. "The good, that is, the well" of a human is the excellent achievement of a human, while the human good is a certain excellent achievement of a human, namely, the best achievement of a human. The best achievement of a human possesses certain better-making features that an excellent achievement of a human need not possess. As Aristotle notes in Nicomachean Ethics II 4, one "excellent achievement" (to eu) can be better than another (1105a10).

Alternative to the Second Assumption: The additional criteria view, not the

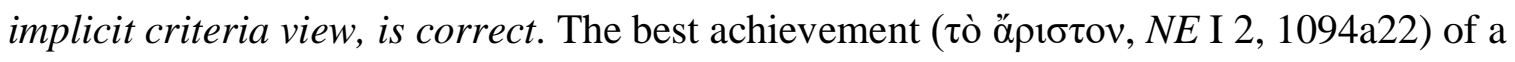
human can be something better than the excellent achievement ( $\tau$ c̀ $\varepsilon \tilde{v}, N E$ I 7, 1097b27) of a human, and consequently the two last additions ("if there is more than one virtue, on the basis of the best and most teleios" and "in a teleios life") serve to mark off the best 
achievement from the merely excellent one. They are not just optional elucidations of "activity of the soul on the basis of virtue," but further requirements that an activity must meet if it is to count as the human good. ${ }^{38}$ Similarly, the addition "of the best genre" is not just an optional elucidation of "poem achieved on the basis of poetic virtue" but a further requirement that a poem must meet if it is to count as the best achievement of a poet. And the addition "of the best subject matter" is not just an optional elucidation of "sculpture achieved on the basis of the virtue of a sculptor" but a further requirement that a sculpture must meet if it is to count as the best achievement of a sculptor.

\section{Alternative to the Third Assumption: For an activity to count as the ergon of a} human it need not involve the activity of both parts of the soul that are said to "have reason" (NE I 7, 1098a3-4) With regard to the interpretation of section $\mathrm{C}$, even though the ergon of a human being is specified as activity of the part of the human soul having reason, where this includes both activity of the part that has reason strictly speaking and activity of the part that has reason as obeying reason, I take it that Aristotle would consider theoretical activity, which is an activity of just the part of that has reason strictly speaking, to be a genuine instance of the human ergon - even though such an activity is separated from the compound of soul and body (cf. $N E$ X 8, 1178a22) and thus need not involve any activity of the obedient part of the soul. ${ }^{39}$ To use our earlier analogy, even though the ergon of poet may be specified as a poem, where poems include tragedy, comedy, lyric, etc., Aristotle would consider just a tragedy on its own to be a genuine instance of the poet's ergon. It is a genuine instance of the poet's ergon even though it is not also a lyric or a comedy. Thus, it is not at all implausible that when Aristotle gives Addition 1 he means to single out a certain activity of the part of the soul that has reason strictly speaking as the best achievement of a human. Likewise, when one attaches the

\footnotetext{
${ }^{38}$ Aquinas 1969, 56, I.10.144-152 similarly explains the addition "on the basis of the best and most teleios virtue" by saying "happiness [felicitas] is not only the good of man but the best good of man." Though it is unclear to me how Aquinas understands the premises of the ergon argument, his statement does seem to commit him to what I have called the additional criteria view.

${ }^{39}$ Commenting on Aristotle's claim at $N E \mathrm{X} 8,1178 \mathrm{a} 22$ that "the virtue of the intellect" (by which Aristotle clearly means theoretical virtue) is "separated" from the compound, Reeve $(2014,348)$ writes, "Theoretical wisdom is separate from the body and the other psychic elements [...] because it is the virtue of something separate from them." For discussion of the separability of intellect in Aristotle's De Anima, see Miller 2012 and Cohoe 2013.
} 
addition "if there are more genres than one, of the best genre," one would be singling out a tragedy or group of tragedies as the best achievement of a poet.

Alternative to the Fourth Assumption: the key explanatory middle term of the argument does not incline one to think that the human good involves both practical and theoretical activity. If we assume that the key explanatory middle term of the ergon argument is "the best achievement of a human" there is no obvious pressure to suppose that the human good involves exercise of all our human capacities. Similarly, I take it, the term "best achievement of a poet" need not incline one to think that such a poetic achievement must involve all genres. Moreover, we can plausibly interpret the ergon argument as having "the best achievement of a human" as its key explanatory middle term precisely because we suppose Aristotle to be employing the alternative concept of an ergon (on which see section 4 above).

\section{Two Clarifications}

I have now given reasons to think that it is both possible and plausible that a monistic reading of the definition of the human good follows from the premises of the ergon argument. To enrich the picture that I have sketched, I now make two clarifications. 


\subsection{The Human Ergon in the Nicomachean Ethics and Eudemian Ethics}

My first clarification is that even if you accept my proposed interpretation of the argument, that does not itself ensure a monistic reading of Aristotle's definition of the human good. This is because it is only retrospectively that one can be confident that "the best and most teleios virtue" refers to a single virtue to the exclusion of others. ${ }^{40}$ This is in turn because it is only retrospectively that we can know that all the virtues-both practical and theoretical—do not unite to form a super 'whole' virtue, whose exercise somehow involves the other virtues. Such a virtue would be the best and most teleios virtue precisely because the part exists for the sake of the whole and thus the whole is better than the part (Pol I 2, 1253a18-29; cf. Meta Z 10, 1034b28-32).

Aristotle apparently believed there was such a super virtue when he wrote the Eudemian Ethics, and that virtue is "kalokagathia" ("nobility-and-goodness"). Consider the following lines from $E E$ VIII 3:

About each virtue individually we have earlier spoken. Now since we have distinguished their powers separately, we must also describe carefully the virtue that [arises] out of these, which we have already been calling 'nobility-and-goodness' [kalokagathia]. That he who truly deserves this denomination must have the individual [kata meros] virtues is clear; it cannot be otherwise with other things either, for no one is healthy in his entire body and yet healthy in no part of it, but the most numerous and important parts, if not all, must be in the same condition as the whole.

$(1248 \mathrm{~b} 8-16)^{41}$

Aristotle here assumes that there is a virtue that arises out of the individual virtues, of which he had "earlier spoken." Aristotle discussed the intellectual virtues in $E E \mathrm{~V}[=N E$ VI], and so they too must presumably be included. ${ }^{42} \mathrm{He}$ identifies this virtue as

\footnotetext{
${ }^{40}$ See Baker forthcoming in which I use Kripke's distinction between speaker's reference and semantic reference in order to explain how the phrase "best and most teleios virtue" might refer to a specific virtue, even though Aristotle (in $N E$ I 7) is not using the phrase to refer to a specific virtue.

${ }^{41}$ This translation is based on that of Solomon in Barnes 1995.

${ }^{42}$ Likewise, Décarie 2007, 272n.74, commenting on 1249a16-17, speaks of kalogathia as "la vertu qui comprend toutes les autres (y compris les vertus intellectuelles) ainsi que l'indiquaient le début du chapitre [1248b8-16] et les passages pertinents de II 1." Here are two further reasons to think that kalokagathia
} 
kalokagathia, which I translate literally as "nobility-and-goodness." This term, which is here being elevated for philosophical use, suggests nobility in an aristocratic sense: that is, the advantages of wealth, good birth, a well-rounded education, and access to leisure time. Thus, in an Aristotelian context it naturally suggests someone who is able both to rule themselves and others (on the basis of character virtue and practical wisdom) but also to use their leisure time well (on the basis of theoretical virtue). By claiming that "nobility-and-goodness" is the whole virtue of which the individual virtues are the parts (EE VIII 3, 1248b8-11) ${ }^{43}$ and by explicitly stating a little later in the same chapter that "nobility-and-goodness is teleios virtue" (1249a16-17), Aristotle apparently identifies the referent of "teleios virtue" in the definition of happiness at $E E$ II 1, 1219a39.

Consequently, Aristotle in the $E E$ does indeed seem to think that the best good is an activity on the basis of all the human virtues, including the virtues of the intellect. However, that is not because it is an activity on the basis of all the virtues, but rather because it is an activity on the basis of a single (most) teleios virtue that nevertheless includes all the others. ${ }^{44}$

In the Nicomachean Ethics Aristotle seems to think that it is possible for one virtue to be composed out of many virtues. In $N E \mathrm{~V}$ (=EE IV) 1 he explains that whole character virtue is composed out of all the virtues of character, and that when it is exercised towards another ( $\left.\pi \rho \mathrm{ò}_{\text {है }} \tau \varepsilon \rho o v\right)$ it is general-justice, and moreover that particular-justice is related to general-justice as part to whole (NE V [=EE IV] 1-2, 1130a9-14). However, the $N E$ does not seem to recognize any whole virtue that is composed out of all virtues, both practical and theoretical. Instead, the book's final chapters, $N E \mathrm{X}$ 6-8, present a sort of rivalry between the best practical virtue (which seems to be general-justice, presumably conjoined with legislative phronesis; cf. $N E \mathrm{~V}$

includes the intellectual virtues. First, Aristotle implies that nobility-and-goodness is composed out of all the virtues or all the most important virtues (EE VIII 3, 1248b11-16) and it is clear that sophia is one of the most important virtues, if not the most important virtue. Second, the conjunction of three extremely plausible claims yields this conclusion: (1) eudaimonia is activity "on the basis of teleios virtue" (EE II 1, 1219a38-39), (2) teleios virtue is the single virtue of nobility-and-goodness (EE VIII 3, 1249a16-17), and (3) the exercise of the theoretical virtues is part of eudaimonia (cf. EE VIII 3, 1249b9-25).

${ }^{43}$ Note also the use of kata meros, which I imperfectly translate as "individual," at EE VIII 3, 1248b8 and b12.

${ }^{44}$ Aristotle in the Politics seems to express a similar view: "the good man, we say, is [good] on the basis of a single virtue, the teleios one" (III 4, 1276b33-34, my emphasis). Similarly, Plato in the Republic speaks of the virtue of a human being as justice (e.g. I, 353e7-8), which he seems to understand as a single virtue. 
[=EE IV] 1, 1129b25-27 and VI [=EE V] 1141b25) and the best theoretical virtue (which is clearly sophia). The activity of the best practical virtue is for the sake of the activity of the unqualifiedly best virtue (which is sophia), in evidence of which Aristotle notes, for example, that in practical virtuous activity we aim "to a greater or lesser extent to gain something beyond the action" ( $N E \mathrm{X} 7,1177 \mathrm{~b} 2-3)$. Here there is no textual reason to think that the best practical virtue forms a part of the unqualifiedly best virtue. Instead, Aristotle explicitly says that the virtue of the theoretical intellect is "separated"

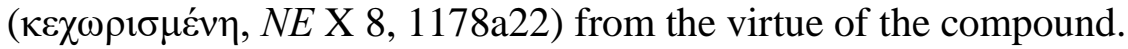

Noting this dissimilarity between the $N E$ and the $E E$ also puts us in a position to diffuse two potential problems. First, at $N E$ VI (=EE V) 12, 1144a6-7 we read:

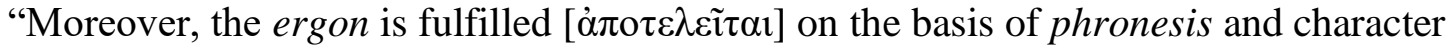
virtue." According to Irwin, this passage "confirms the claim in I 7 that happiness has to include the harmony of the non-rational but obedient part with the inherently rational part." ${ }^{45}$ Now I think that when read in context this elliptical line does not force upon one the conclusion, implicitly drawn by Irwin, that the second assumption mentioned above is true, namely that any full instance of the human ergon must involve both the activity of the part of the soul that obeys reason and the activity of the part that actually has reason and thinks. ${ }^{46}$ However, even if one did think this, one should be wary of imposing this conclusion on the $N E$ ergon argument. That is because $N E \mathrm{VI}(=E E \mathrm{~V})$ is a book common to both the $N E$ and the $E E$, and as a growing scholarly consensus maintains, the common books were originally written for inclusion in the $E E \cdot{ }^{47}$ Moreover, parts of the common books seem to have been imperfectly revised for their inclusion in the $N E$, and thus

\footnotetext{
${ }^{45}$ Irwin 2012, 519. Roche 1988, 182 also makes this argument.

${ }^{46} N E \mathrm{VI}(=E E \mathrm{~V}) 12$ begins by noting several reasons one might have for thinking that being happy (eudaimon) does not require either sophia or phronesis. At 1143b21-28 Aristotle asks why we need phronesis if it makes the person with character virtue no more likely to do good and just actions. Because the passage quoted above (1144a6-7) is, I take it, part of his answer to this question, there is good reason to think that "the ergon" at 1144a6 should be glossed not just as "the human ergon" but more particularly as "the human practical ergon." On this reading, Aristotle would be answering his earlier worry by responding that yes, one does also need phronesis because "the [human practical] ergon is fulfilled on the basis of phronesis and character virtue: for virtue makes the goal correct, and phronesis makes the means to this goal correct" (1144a6-9). This sort of reading does make the text somewhat elliptical, and I acknowledge that Aristotle elsewhere shows himself capable of qualifying what sort of ergon he has in mind (e.g. NE VI 2, 1139a27-29). However, the text is elliptical even on an inclusivist reading such as Irwin's. This is because on Irwin's reading, theoretical activity is also part of the human ergon, in which case Aristotle should really be saying that the ergon is achieved on the basis of phronesis, character virtue, and sophia. ${ }^{47}$ See e.g. Kraut 1997, 129-130 and 2002, 16-19 for an articulation of this view.
} 
sometimes retain some $E E$ views that are not fully compatible with those in the $N E{ }^{48}$ Given what we earlier noted about the $E E$ 's view of the best good, i.e. that happiness is an activity of a super virtue that somehow involves all the other virtues, one could reasonably argue that $N E \mathrm{VI}(=E E \mathrm{~V}) 12,1144 \mathrm{a} 6-7$ is one such imperfectly revised passage.

Second, Ackrill argued that since the definition of happiness at EE II 1 should be interpreted inclusively, we should likewise interpret the definition of the human good at $N E$ I 7. According to the EE, "happiness would be the activity of a teleios life on the basis of teleios virtue" (II 1, 1219a38-39), and Ackrill claimed that when the EE ergon argument speaks of "teleios virtue" Aristotle means "complete virtue," in the sense of "all virtues." 49 However, there is good reason to question this. Just a few lines earlier in EE II 1, Aristotle explains what he has in mind by "teleios virtue" by noting that "virtue may be

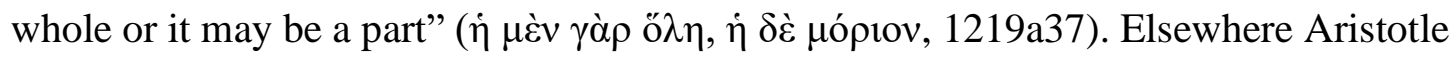
takes it to be clear that the whole is ontologically prior to its parts (e.g. Pol I 2, 1253a20), and so it is not plausible to understand teleios virtue as the complete collection of individual virtues. ${ }^{50}$ Instead, we should expect teleios virtue to be a single whole virtue that is ontologically prior to the individual virtues, which it has as parts. And as we have already seen, the EE goes on to identify "teleios virtue" as nobility-and-goodness - a whole virtue that is composed out of all the individual virtues ( $E E$ VIII 3, 1249a16-17). ${ }^{51}$

\footnotetext{
${ }^{48}$ Lorenz 2009, for example, argues for an imperfect Nicomachean revision of $N E$ VII (=EE VI). See also Gauthier and Jolif (1970) 2002, who give good reasons to think that $N E$ VI (=EE V) is an imperfect Nicomachean revision. Like these authors, I think we should not entirely dismiss the evidence from the common books when interpreting the doctrines of the $N E$, but that we should be circumspect in the way that we use that evidence.

${ }^{49}$ Ackrill 1980, 27.

${ }^{50}$ However, since ontological priority only seems to hold for natural wholes and not for artifacts (cf. perhaps Top VI 13, 150a33-36), one might think the priority does not hold for whole virtue. A full discussion of this point falls outside the scope of this paper, but I will note that virtue does seem to be natural insofar as it is the perfection (teleiōsis) of our nature, and insofar as we have a natural inclination to acquire it (NE I 7, 1098a15; II 1, 1103a25). Cf. Leunissen 2015. Moreover, Aristotle seems to think that the individual character virtues cannot exist apart from one another or from phronesis (NE VI [ $=E E \mathrm{~V}] 13$, $1144 \mathrm{~b} 30-1145 \mathrm{a} 2)$, and so here too there seems to be an ontological priority of whole character virtue (NE V [=EE IV] 1130a11-13).

${ }^{51}$ Thus, Aristotle would identify teleios virtue kalokagathia because this virtue is teleologically highestsince the part exists for the sake of the whole. (On this reading, the different ways of being teleios as listed in Metaphysics $\triangle 16$ are not mutually exclusive.) Though I will not discuss this point here, I believe Aristotle's use of teleios in the phrase "teleios life" (at EE II 1, 1219a38-39 and NE I 7, 1098a18) can also be interpreted teleologically for the same reason. The word then means something like "perfect" (not
} 
However, Ackrill and others do not maintain that the human good is an activity on the basis of all the virtues because there is some super whole virtue. ${ }^{52}$ Consequently, their inclusivist reasoning finds no precedent in the $E E .^{53}$

\subsection{Eudaimonia and The Human Good}

My second clarification is that even if you accept a monistic reading of the definition of the human good, that does not require you to be a monist about eudaimonia or even about the human good itself. (What I am about to say I can only offer as a sketch.)

Let us begin by considering the remarks that Aristotle makes about eudaimonia in the last chapters of the $N E$. By means of various arguments, which we will not go through, Aristotle concludes that the contemplative life is the happiest, while the political life is happy only in a secondary way (X 8, 1178a9).${ }^{54}$ Likewise, the activity of theoretical wisdom is the primary form of human eudaimonia (cf. X 7, 1177a12-b26), while the activity of the best practical virtue, which I take to be the activity of general justice, seems to be only a secondary form of human eudaimonia (cf. X 8, 1178a20-22).

\footnotetext{
"complete"), though being "complete" is one way of being "perfect." On this interpretation, the French "achevé," as used by Gauthier and Jolif (1970), seems apt.

${ }^{52}$ The exception may be Irwin 2012, 518, who in arguing for his inclusivist interpretation of Aristotle's definition of the human good in $N E$ I 7, writes: "But if we understand completeness by reference to the relation between a whole and its parts, Aristotle's claim about the most complete end and the most complete virtue are reasonable. His preference for the singular ('complete virtue') over the plural ('all the virtues') is reasonable in the light of his conception of wholes. Even if happiness includes all virtuous activities, acting for the sake of happiness is an integrated activity that combines virtuous activities in an organized way of life." Here Irwin perhaps commits himself to the view that in the $N E$ there is a single "whole" virtue of which the other virtues are "parts." Though he offers no direct textual evidence that there is such a virtue, one could cite $N E \mathrm{VI}(=E E \mathrm{~V}) 12,1144 \mathrm{a} 5$ where Aristotle seems to suggest there exists a "whole virtue" of which sophia is a part. Given the interpretation that I have advanced, I suspect that either Aristotle is here speaking very loosely or that this is an $E E$ passage that was imperfectly revised for its inclusion in the $N E$.

${ }^{53}$ Is the view that I discern in the $E E$ a version of monism or inclusivism? I think the most reasonable answer is: it is not obvious. The reason is that the view does not seem to easily fit into the terms of the traditional debate. On the one hand, it seems to be a version of monism insofar as happiness is the activity of a single virtue - and thus Charles 2015, 62, who briefly considers this sort of position in the abstract, considers it a form of monism. On the other hand, it seems to be a version of inclusivism insofar as happiness involves the activity of all the virtues - and thus Irwin 2012, 518, who comes very close to attributing such a view to the $N E$, seems to consider it a form of inclusivism.

${ }^{54}$ The word "happy" is actually omitted at $N E \mathrm{X} 8,1178 \mathrm{a}$, but it seems like it should be supplied from the previous line, as Lear 2004, 176n.2 suggests. Yet is perhaps defensible to supply "happiest" instead, as Broadie 1991, 438n.72 contends.
} 
Taken at face value, these remarks suggest that Aristotle is neither a monistic nor an inclusivist about eudaimonia. On the one hand, Aristotle is not an inclusivist about eudaimonia because he does not claim that the best good is a certain conjunction of practical and theoretical activity. ${ }^{55} \mathrm{He}$ could have easily said this, as he seems to in the last chapters of the $E E$, but he does not. On the other hand, he does not seem to be a monist because he clearly claims that the activity of general justice is a genuine case of eudaimonia, though it has less the character of eudaimonia than the activity of theoretical wisdom. He seems to be instead what I will call a "gradationist." Such an interpretation is, I believe, confirmed by Aristotle's claim that the God's eudaimonia is "superior in blessedness" to our own (X 8, 1178b22, cf. I 10, 1101a19-21 and Meta $\Lambda$ 7, 1072b2426). We thus have in the $N E$ at least three things that are called eudaimonia, and they can be ranked in relation to one another: the contemplative activity of God is better than the life-long human activity of theoretical wisdom, which is in turn better than the life-long human activity of general justice. Moreover, Aristotle claims that human activities have the character of eudaimonia only to the degree that they are akin to God's activity (NE X 8, 1178b22-24; cf. Cael II 12). God's activity is then the primary case of happiness, and any other activity will be called "happiness" to the extent that it relevantly approximates that activity. ${ }^{56}$

But does this mean that Aristotle is a gradationist about the human good? I think that one can defensibly answer "yes" or "no."

If one were to answer "no," then one would of course need to pry apart what it is to be the human good and what it is to be eudaimonia. This is exegetically possible and

\footnotetext{
${ }^{55}$ I am ignoring the possibility that Aristotle is a "total-inclusivist"- that is, someone who believes that happiness consists in virtuous activity as well as in other goods. Such a position can be subdivided into those who think that virtuous activity is the "principle component of happiness" (Broadie, 2002, 286), and those who think that happiness is alone virtuous activity but that such activity is partly constituted by goods such as health (e.g. Crisp 1994). See Heinamen 2007 for this distinction as well as for powerful arguments that happiness in the $N E$ is always understood as an activity to the exclusion of other goods.

${ }^{56}$ In articulating this gradationist reading of eudaimonia, I take myself to be developing thoughts already defended in the literature. For example, Charles 1999 and 2015 argues that the human activity of theoretical wisdom is the central (or paradigm) case of happiness, but that there are other instances as well. Scott 1999 and Bush 2008 are what Bush calls "dualists" since they both acknowledge two kinds of eudaimonia in the $N E$ : virtuous practical activity and virtuous contemplative activity. Lear 2004 understands virtuous contemplative activity to be in some sense a paradigm for other virtuous human activity, but she argues that a strict teleological conception of the human good requires monism. Long 2012 advances a gradationist view, making the activity of God the primary case of eudaimonia, but he considers Aristotle's overall argument in the $N E$ to be "structurally flawed" (113). Bush 2008, Charles 2015 and Long 2012 all agree with Lear in different ways, but none of them seems to wrestle with her teleological arguments for monism.
} 
even desirable. It is possible because Aristotle would seem to use the phrase "the human good" as a special label for the best, i.e. teleologically highest, good achievable in action by human beings (I 2, 1094b7). Yet when Aristotle identifies eudaimonia with the best and most teleios end (I 7, 1097a34), he does not use a deductively valid argument but an "inference from a sign." 57 He thus leaves it open how exactly we should think of the relationship of the human good and eudaimonia.

This interpretation seems to be desirable because eudaimonia and the human good are not coextensive. First, the gods possess eudaimonia, but this is far superior to what humans achieve in action, and so should not be equated with the human good (Meta $\Lambda 7$, 1072b24-26; cf. NE X 8, 1178b22-23, and I 10, 1101a19-21). Second, the activity of general justice is called eudaimonia (NE X 8, 1178a21-22) but there is good reason to think that it cannot be the best thing achievable in action by humans: it essentially aims at something beyond itself, and so does not have the right teleological structure to be the best and most teleios end (NE X 7, 1177b17-18). ${ }^{58}$ Consequently, one has reason to be a monist about the human good but a gradationist about eudaimonia.

This sort of position allows one to accommodate some of the key motivations of both monists and inclusivists. On the one hand, there is agreement with those monists who persuasively argue that the human good, in virtue of being the best and most teleios end, cannot include within it practically virtuous activity. ${ }^{59}$ Because the conclusion of the ergon argument is offered as a definition of the human good, it should then be interpreted monistically. The human good, which is the primary case of human eudaimonia, is an activity of theoretical wisdom ("the best and most teleios virtue") carried out over an optimal natural lifespan. On the other hand, there is agreement with those inclusivists who refuse to deny that the activity of moral virtue carried out over a whole life is a genuine case of eudaimonia. ${ }^{60}$ The gradationist picture also allows us to make sense of Aristotle's later reformulations of his definition-reformulations for which

\footnotetext{
57 "Eudaimonia especially [malista] seems to be this sort of thing” (NE I 7, 1097a34). Cooper (2003) 2004, 281-282 argues for this point.

58 See the arguments of Lear 2004.

59 Thus, I am sympathetic with the arguments advanced by Cooper (2003) 2004 and Lear 2004.

${ }^{60}$ Bush 2008 correctly observes that the monistic reasoning of Cooper (2003) 2004 and Lear 2004 leads them to deny that virtuous practical activity can in any way constitute eudaimonia. However, they still want to claim that the person who engages in such an activity is happy, but only because he is organizing his life by reference to the best and most teleios end, which is theoretically wise contemplation.
} 
strict monistic interpretations seem procrustean at best. ${ }^{61}$ Take, for example, NE I 13, 1102a5-7: "Since eudaimonia is some activity of the soul on the basis of teleios virtue, we should examine virtue, for perhaps in this way we will better see what eudaimonia is." Because this is presented as a definition of (human) eudaimonia and not of the human good, one is free to hear it as something that could be satisfied to different degrees. When Aristotle here speaks of "teleios virtue" (NE I 13, 1102a6), that phrase may be satisfied by whole character virtue ( $N E \mathrm{~V} 1,1130 \mathrm{a} 11-13)$, satisfied still better by

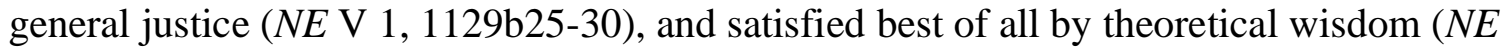
X 7, 1177a24).

However, the picture that I have just presented does have the odd sounding result that a ethically virtuous person might attain human eudaimonia, albeit to a secondary degree, while at the same time failing to attain the human good. This might incline one want to subscribe to gradationism about both human happiness and the human good. If we want to read the $N E$ I 7 definition as compatible with this sort of view, then we would need to understand Aristotle to be offering that definition by reference to the best and primary case of the human good. ${ }^{62}$ Aristotle does seem to adopt a method like this elsewhere (e.g. Pol I 5, 1254a36-39), and it is not unreasonable. For example, when we give an account of the human body, we should look to the best case and note that the body has e.g. two arms and two legs, even if we are also prepared to admit that there are human bodies without this number of limbs. Similarly and more aptly for our purposes, when we give an account of health, we should do so by reference to the best case of health, even if we also think that health comes in degrees and that some states of the body, which fall below this best case, should still be called "health" (cf. Cael II 12, 292b13-19; NE X 3, 1173a24-25). Thus, we should understand the end of the medical art to be the best case of health (cf. Pol I 9, 1257b25-28), even though the doctor will often have to settle for producing a much lower degree of health in many of his patients.

\footnotetext{
${ }^{61}$ See Lawrence 1993, 29n.31 for an intelligent but defeated attempt to reconcile the reformulations with a monistic reading of the full definition in NE I 7.

62 Broadie 2002, 278 would seem to recommend reading the definition in NE I 7 along these lines. Here I should also clarify that I do not think that one can hear the definition of NE I 7 as being satisfied to different degrees, even though I do think that one might hear the definition at NE I 13 in this way. The reason is because, in $N E$ I 7, in order for the phrase "best and most teleios virtue" to refer to general justice, one must restrict the virtues in question to character virtues, but by so doing you would change the meaning of the phrase "best and most teleios virtue."
} 
Similarly, we should understand the end of political wisdom to be the best case of the human good, which is a sufficiently long activity of theoretical wisdom, even though the legislator will often have to settle for producing some much lower degree of the human good for many in the polis. ${ }^{63}$

\section{Conclusion}

I take this paper to be the first serious response to Ackrill's influential claim that the definition of the human good can follow from the premises of the ergon argument only if it is interpreted along inclusivist lines. I have articulated the key assumptions that have lead Ackrill and others to make this claim (or similar claims), and I have also explained how one might reasonably deny the assumptions. One of the linchpins of my argument has been to assume that Aristotle in $N E$ I 7 is using the alternative concept of an ergon - on which the ergon of an X may be a proper activity or a proper product (i.e. something produced beyond a proper activity), depending on what the $\mathrm{X}$ is. This concept allows the key explanatory middle term of the argument to be "the best achievement of a human," and it allows for an interpretation on which the final two additions ("on the basis of the best and most teleios virtue" and "in a teleios life") are not optional clarifications but further requirements that something must meet if it is to count as the human good. On such a reading, I contend, a monistic reading of the definition can indeed follow from the premises of the ergon argument. In order to respond to some potential objections, I have sketched a broader picture of Aristotle's theory of eudaimonia and the human good, and on that picture, anyone reading the definition in $N E$ I 7 retrospectively will have reason to read it monistically.

A few closing remarks on my interpretation are now perhaps in order. First, Aristotle makes the additions "on the basis of the best and most teleios virtue" and "in a teleios life" in order to distinguish the best achievement of a human from a merely excellent one. This allows for the possibility that Aristotle might need to add yet further criteria in order to more accurately "narrow in" on the best achievement of a human, and

\footnotetext{
${ }^{63}$ Thus, on the gradationist picture that I propose, the practically wise person would not have a problematic "dual focus" on two teleologically unrelated ends-which is something that Lear 2004, 88-90 critiques in the accounts of Charles 1999 and Scott 1999.
} 
he perhaps does just this in $N E$ I 11 when he makes the addition "adequately furnished with external goods" (1101a15, cf. I 8, 1099a31-32). Second, "the best achievement of a human" should be understood as absolutely best achievement of a human. That is, Aristotle in the ergon argument crucially relies on some notion of absolute goodnessgoodness that is not reducible to "goodness in a kind" or "good for something." Aristotle clearly relies on a notion of absolute goodness elsewhere in the $N E$, where for example, he argues that sophia is better than phronesis precisely because the objects of sophia are better and "more divine" than the objects of phronesis (NE VI 7). Thus, even though the human good is somehow relative to a human, its goodness does not merely consist in being relative to a human: it is also somehow absolutely good. ${ }^{64}$ Third and lastly, the reasoning that I detect in the ergon argument is perhaps alone compatible with a straightforward reading of Aristotle's exhortation "to put on immortality as much as

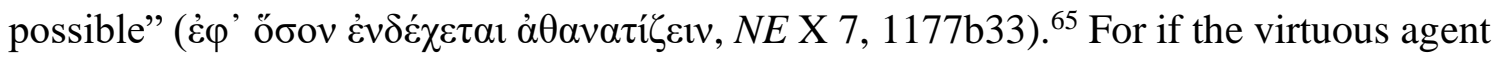
desires the absolutely best thing that he can achieve, and the divine is the standard for all

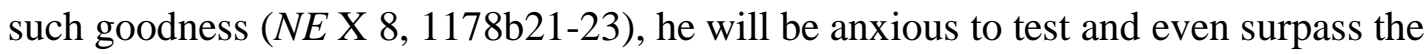
limits of human nature - so long of course as he remains himself (NE IX 4, 1166a1923). ${ }^{66}$

\section{Abbreviations}

Cael De Caelo [On the Heavens]

EE Eudemian Ethics

Meta Metaphysics

NE Nicomachean Ethics

MM Magna Moralia

PA Parts of Animals

Phys Physics

Pol Politics

\footnotetext{
${ }^{64}$ See Baker 2017 in which I argue contra Kraut 2011, 210-21 that some notion of absolute goodness is integral to the argument of Aristotle's Nicomachean Ethics.

${ }^{65} \mathrm{I}$ have in mind the sort of reading that is given by e.g. Sedley 2000, 324-328.

${ }^{66}$ For helpful comments on various versions of this paper, I thank Marjolein Oele, Benjamin Morison, Hendrik Lorenz, John Cooper, Victor Caston, three anonymous referees, and audiences at the University of South Alabama and the 2014 Bay Area Colloquium in Ancient Philosophy.
} 
Post Posterior Analytics

Top Topics

\section{Bibliography}

Achtenberg, D. 1989. “The Role of the Ergon Argument in Aristotle's Nicomachean Ethics". Ancient Philosophy 9, 1: 37-47.

Ackrill, J. L. (1974) 1980. “Aristotle on Eudaimonia.” In Essays on Aristotle's Ethics. Ed. A. O. Rorty. Berkeley, CA. (Originally in the Proceedings of the British Academy 60).

Anagnostopoulos, A. 2017. "Change, Agency and the Incomplete in Aristotle". Phronesis 62, 170-209.

Aquinas, T. 1969. Sententia Libri Ethicorum. Rome. Vol. 47 of T. Aquinas. (1882ongoing). Opera Omnia iussu Leonis XIII P. M. Edita. Rome/Paris.

Aufderheide, J. 2015. "The Content of Happiness: A New Case for Theoria". In The Highest Good in Aristotle and Kant. Ed. J. Aufderheide and R. Bader. Oxford, 3659.

Baker, S. 2015. "The Concept of Ergon: Towards an Achievement Interpretation of Aristotle's 'Function Argument'”. Oxford Studies in Ancient Philosophy 48, 229268.

Baker, S. 2017. "The Metaphysics of Goodness in the Ethics of Aristotle". Philosophical Studies 174, 1839-56.

Baker, S. forthcoming. "What is the 'best and most perfect virtue'?". Analysis, published online September 10, 2018: https//doi.org/10.1093/analys/any064

Barnes, J. (ed.) (1984) 1995. The Complete Works of Aristotle. Volumes 1-2. Princeton.

Barney, R. 2008. “Aristotle's Argument for a Human Function”. Oxford Studies in Ancient Philosophy 34, 293-322.

Broadie, S. 1991. Ethics with Aristotle. Oxford.

Broadie, S. (comm.) and C. Rowe (trans.). 2002. Aristotle: Nicomachean Ethics: Translation, Introduction and Commentary. Oxford.

Bush, S. 2008. "Divine and Human Happiness in Nicomachean Ethics". The 
Philosophical Review 117, 49-75.

Charles, D. 1999. "Aristotle on Well-Being and Intellectual Contemplation". Proceedings of the Aristotelian Society Supplementary Volume 73, 205-223.

Charles, D. 2015. "Aristotle on the Highest Good: A New Approach". In The Highest Good in Aristotle and Kant. Ed. J. Aufderheide and R. Bader. Oxford, 60-82.

Cleemput, G. 2006. "Aristotle on Eudaimonia in Nicomachean Ethics I". Oxford Studies in Ancient Philosophy 30,127-157.

Cohoe, C. 2013. "Why the Intellect Cannot Have a Bodily Organ: De Anima 3.4". Phronesis 58, 347-377.

Cooper, J. (1987) 1999. “Contemplation and Happiness: A Reconsideration.” In his Reason and Emotion: Essays on Aristotle's Moral Psychology and Ethical Theory. Princeton, 212-236. (Originally in Synthese 72.)

Cooper, J. (2003) 2004. "Plato and Aristotle on 'Finality' and '(Self-)Sufficiency'”. In his Knowledge, Nature and the Good. Princeton, 270-308. (Originally in Plato and Aristotle's Ethics. Ed. R. Heinaman. London.)

Cooper, J. 2012. Pursuits of Wisdom: Six Ways of Life in Ancient Philosophy from Socrates to Plotinus. Princeton.

Crisp, R. 1994. “Aristotle's Inclusivism”. Oxford Studies in Ancient Philosophy 12, 111136.

Curzer, H. 1990. "Criteria for Happiness in Nicomachean Ethics I 7 and X 6-8". Classical Quarterly 40, 421-432.

Décarie, V. (1978) 2007. Aristote: Éthique à Eudème. Paris.

Foot, P. 2001. Natural Goodness. Oxford.

Gauthier, R. A. \& Jolif, J. Y. (1970) 2002. L'Éthique à Nicomaque: Introduction, Traduction, et Commentaire. $2^{\text {nd }}$ Ed. Volumes 1-4. Louvain.

Glassen, P. 1957. "A Fallacy in Aristotle's Argument about the Good". The Philosophical Quarterly 7, 319-322

Gomez-Lobo, A. 1989. "The Ergon Inference”. Phronesis 34, 170-184.

Gottlieb, P. 2009. The Virtue of Aristotle's Ethics. Cambridge.

Hardie, W. F. R. 1965. "The Final Good in Aristotle's Ethics" Philosophy 40, 277-295. 
Heinaman, R. 1988. "Eudaimonia and Self-Sufficiency in the Nicomachean Ethics". Phronesis 33, 31-53.

Heinaman, R. 2007. “Eudaimonia as an Activity in Nicomachean Ethics 1.8-12”. Oxford Studies in Ancient Philosophy 33, 221-253.

Hutchinson, D. S. 1986. The Virtues of Aristotle. London.

Irwin, T. H. (trans.) 1999. Aristotle: Nicomachean Ethics, Translated with Introduction, Notes and Glossary. $2^{\text {nd }} \mathrm{Ed}$. Indianapolis and Cambridge.

Irwin, T. H. 2012. "Conceptions of Happiness in Aristotle's Nicomachean Ethics”. In Ed. Shields, C. The Oxford Handbook of Aristotle. Oxford, 495-528.

Joachim, H. H. (1951) 1962. Aristotle: The Nicomachean Ethics. Oxford.

Johansen, T. J. 2012. The Powers of Aristotle's Soul. Oxford.

Kenny, A. 1992. Aristotle on the Perfect Life. Oxford.

Keyt, D. 1983. "Intellectualism in Aristotle”. In Essays in Ancient Greek Philosophy. Ed. J. P. Anton and A. Preus. Volume 2. Albany, 364-387.

Kraut R. 1979. “The Peculiar Function of Human Beings”. Canadian Journal of Philosophy 9, 467-478.

Kraut, R. 2002. Aristotle: Political Philosophy. Oxford.

Kraut, R. 1997. Aristotle: Politics Books VII and VIII: translation with commentary. Oxford.

Kraut, R. 2009. What is Good and Why: The Ethics of Well-Being. Cambridge.

Kraut, R. 2011. Against Absolute Goodness. Oxford.

Lawrence, G. 1993. "Aristotle on the Ideal Life". Philosophical Review 102, 1-34.

Lawrence, G. 2006. "Human Good and Human Function". In The Blackwell Guide to the Nicomachean Ethics. Ed. R. Kraut. Malden, 37-75.

Lawrence, G. 2009. 'Is Aristotle's Function Argument Fallacious? Part 1: Clarification of Objections". Philosophical Inquiry 31, 191-224.

Leunissen, M. 2015. "Perfection and the physiology of habituation according to Physics VII.3”. In Aristotle’s Physics: A Critical Guide. Ed. M. Leunissen Cambridge, 225-244.

Lear, G. 2004. Happy Lives and the Highest Good: An Essay on Aristotle's Nicomachean Ethics. Princeton. 
Long, A. 2013. "Aristotle on eudaimonia, nous, and divinity," in Aristotle's Nicomachean Ethics: A Critical Guide. Ed. J. Miller. Cambridge, 92-113.

Lorenz, H. 2009. "NE VII 4: plain and qualified akrasia". In Aristotle's Nicomachean Ethics Book VII (Symposium Aristotelicum). Ed. C. Natali. Oxford, 72-101.

Louis, P. 1956. Aristote. Les parties des animaux. Paris.

McDowell, J. (1980) 2002. "The Role of Eudaimonia in the Nicomachean Ethics." In Essays on Aristotle's Ethics. Ed. A. O. Rorty. Berkeley, 359-379. (Originally published in the Proceedings of the African Classical Associations 15)

Miller, F. D. 2012. "Aristotle on the Separability of Mind". In The Oxford Handbook of Aristotle. Ed. Shields, C. Oxford. 306-339.

Minio-Palluello, L. (ed.) 1974. Aristoteles Latinus: Vol XXVI.1-3: Ethica Nicomachea. Leiden.

Müller, J. 2003. "Ergon und Eudaimonia: Plädoyer für eine unifizierende Interpretation der ergon-Argumente in den aristotelischen Ethiken". Zeitschrift für philosophische Forschung 57, 513-542.

Moss, J. 2014. "Right Reason in Plato and Aristotle: On the Meaning of Logos". Phronesis 59, 181-230.

Natali, C. 2010. "Posterior Analytics and the Definition of Happiness in NE I". Phronesis $55,305-324$.

Pakaluk, M. 2005. Aristotle's Nicomachean Ethics: An Introduction. Cambridge.

Purinton, J. 1998. "Aristotle's Definition of Happiness (NE 1.7 1098a16-18)". Oxford Studies in Ancient Philosophy 16: 259-297.

Reeve, C. D. C. (trans.) 2014. Aristotle: Nicomachean Ethics, Translated with Introduction and Notes. Indianapolis and Cambridge.

Roche, T. 1988. "Ergon and Eudaimonia in Nicomachean Ethics I: Reconsidering the Intellectualist Interpretation.” Journal of the History of Philosophy 26, 175-194.

Roche, T. 2014. "The Private Life of Aristotle's Philosopher: A Defense of a NonIntellectualist Interpretation of Nicomachean Ethics 10.7-8". In Theoria: Studies on the Status and Meaning of Contemplation in Aristotle's Ethics. Ed. P. Destrée and M. Zingano. Leuven, 207-239. 
Sedley, D. 2000. "The Ideal of Godlikeness". In Plato 2: Ethics, Politics, Religion and the Soul. Ed. G. Fine. Oxford.

Scott, D. 1999. "Primary and Secondary Eudaimonia". Aristotelian Society Supplementary Volume 73, 225-242.

Scott, D. 2015. Levels of Argument: A Comparative Study of Plato's Republic and Aristotle's Nicomachean Ethics. Oxford s[s:

Walker, M. 2011. "Aristotle on Activity 'According to the Best and Most Final' Virtue". Apeiron 44, 91-110. 